\title{
MYCOPLASMAS HYORHINIS IN DIFFERENT REGIONS OF CUBA. DIAGNOSIS
}

\author{
Evelyn Lobo $^{1 *}$, Carlos Poveda ${ }^{2}$, Alejandro Suarez ${ }^{2}$, Yenney Hernández ${ }^{1}$, Ana Ramírez ${ }^{2}$, José B. Poveda² \\ ${ }^{1}$ Laboratorio de Diagnóstico de Micoplasmas (MYCOLAB), grupo de Biología Molecular, Dirección de Microbiología, CENSA, \\ Cuba; ${ }^{2}$ Laboratorio de Diagnóstico de Micoplasmas, Instituto Universitario de Sanidad Animal (IUSA), Universidad de Las \\ Palmas de Gran Canaria, España.
}

Submitted: February 10, 2010; Approved: January 13, 2011.

\begin{abstract}
M. hyorhinis is considered one of the etiological agents of arthritis in sucking pigs, but recently as seen, some strains can produce pneumonia that could not be distinguished from the mycoplasmosis caused by $M$. hyopneumoniae. The study was conducted to research the presence of Mycoplasma hyorhinis (M. hyorhinis ) in different regions of the country from exudates of pig lungs with typical EP lesions. Exudates from 280 pig lungs with typical EP lesions were studied using molecular techniques such as PCR, real time PCR and amplification of the 16S-23S rRNA. It was detected that the $66 \%$ of the samples studied resulted positive to M. hyorhinis, and the presence of this species was detected in all the provinces. Amplification and studies on the intergenic region 16S-23S of $M$. hyorhinis rRNA demonstrated the existing variability among strains of a same species. This study is the first report on M. hyorhinis detection in Cuba.
\end{abstract}

Key words: PCR, mycoplasma, diagnostic, enzootic pneumonia

There are about 17 Mollicutes species that can be isolated from swine. Some of them are recognized as pathogenic, but others may be present in an occasional way and their pathogenic capability for this animal species is unknown (5). Mycoplasma hyopneumoniae, Mycoplasma hyorhinis, Mycoplasma hyosynoviae and Mycoplasma flocculare highlight due to their importance. They can cause infections in the respiratory track, joints, eyes and genital track, and with a higher consideration, there are those infections related to pneumonic processes (16).

M. hyorhinis is considered one of the etiological agents of arthritis in sucking pigs (9); however, in inoculation studies of this microorganism in young gnotobiotic pigs, some $M$. hyorhinis strains produced mild catarrhal pneumonia with gross and microscopic lesions that could not be distinguished from the mycoplasmosis caused by M. hyopneumoniae (12). The diagnosis of this microorganism is carried out by means of the microbiological culture, serology and molecular techniques such as the polymerase chain reaction (PCR) (4).

In Cuba, $M$.hyopneumoniae circulation has been studied from direct lung exudates and its seroprofile has been determinate $(14,1)$, but no further studies have been carried out in the presence of other swine mycoplasmas that may be circulating in the island, hence the objective of the present 
work was to detect the presence of $M$. hyorhinis in different regions of the country from exudates of pig lungs with typical Enzootic Pneumonia (EP) lesions.

A total of 280 pig lungs with typical EP lesions (35 per province) was processed between October, 2007, (Pinar del Río, La Habana, Matanzas) and January, 2008, (Cienfuegos, Villa Clara, Ciego de Avila, Sancti Spiritus and Camagüey). These samples were taken in the regional slaughterhouse $\mathrm{La}$ Española. In all cases, lungs were transported to MYCOLAB with the transfer conditions established by biosafety (in nylon bag biohazard biosafety in refrigerated containers) to be immediately processed.

The samples were taken in the apical, frontal, medial and diaphragmatic lobules. They were processed as follows. A piece of lung lobule that had been previously introduced into $96^{\circ}$ alcohols was flamed, and an incision was made using a flamed scalpel to reach the lung parenchyma with a sterile swab, thus avoiding contamination due to manipulation. The swabs were introduced into eppendorff tubes containing $250 \mu \mathrm{L}$ of sterile PBS and centrifuged at 14 000rpm for 2 minutes. The liquid obtained by this centrifugation was collected for mycoplasma DNA extraction.

The DNA extraction was accomplished according to Fernández (8). It is based on sample subjection to a combination of thermal shocks and centrifugation. PCR, Real Time PCR and amplification of the intergenic region of the 16S-23S rRNA were used for detecting mycoplasma species. The PCR for M. hyorhinis was done as described by Caron (7). The primers for the PCR were synthesized by Sigma-Genosys Ltd. at a concentration of $25 \mathrm{pM}$. Their sequences were:

\section{Mhyr 1 5' GTA GTC AAG CAA GAG GAT GT3' Mhyr 2 5'GCT GGA GTT ATT ATA CCA GGA 3'}

The mixture was prepared using the KIT PuRetaq ${ }^{\mathrm{TM}}$ Ready-To-Go PCR Beads, from BIO_RAD; amplification was done in a volume of $25 \mu \mathrm{L}$, in each case, $1 \mu \mathrm{L}$ of each primer,
$18 \mu \mathrm{L}$ of ultra pure water and $5 \mu \mathrm{L}$ of the problem DNA. For each reaction, DNA from the reference strain $M$. hyorhinis (NCTC 10130) was used as the positive control; sterile bidistilled water was used as the negative control. The protocol used for the Real Time PCR was that described by Assuncao (4), using the Kit QuantiTect SYBR green PCR kit; Qiagen and the PCR for amplification of the intergenic region of the $16 \mathrm{~S}-23 \mathrm{~S}$ rRNA was following the protocol described by Johansson (11).

Real Time PCR has been increasingly used as a diagnostic technique in the last years due to the advantages it offers when compared with PCR. A higher sensitivity reducing the risk of false negative results is its main advantage; in addition to the fact that data are taken in the exponential phase of the process, assuring that amplification may not be limited by any component. It is also faster and with lower probabilities of contamination reducing the false positive results (20).

In our case, the use of this assay allowed to detect that the $66 \%$ of the samples studied resulted positive to M. hyorhinis and the $19.84 \%$ resulted samples mixed with $M$. hyopneumoniae. The high percentage of positiveness to $M$. hyorhinis of the samples agrees, with what was pointed out by Lin (13) and Volokhov (21), who referred to the high sensitivity of the Real Time PCR and its use in this kind of diagnosis and, on the other hand, with Lin (13) who pointed out the high detection frequency of this agent in lung and tonsil samples of pigs.

The percentage of samples that resulted mixed with $M$. hyopneumoniae coincided with that reported by $(4,17)$, who referred to $M$. hyohrinis as the major contaminant of the microbiological cultures of $M$. hyopneumoniae, and to its high incidence as another agent inside the etiological picture and in the characteristic lesions of EP, respectively. The percentage of samples positive to $M$. hyorhinis in the different regions studied can be seen in Table 1. The highest number of positive samples corresponded to the province of Cienfuegos. 
Table 1. Detection of $M$. hyorhinis in different regions of Cuba.

\begin{tabular}{|ll|}
\hline Provinces & positives \\
\hline Cienfuegos & $66.6 \%$ \\
\hline Ciego de Ávila & $50 \%$ \\
\hline Matanzas & $50 \%$ \\
\hline La Habana & $41.6 \%$ \\
\hline Villa Clara & $40.0 \%$ \\
\hline Camagüey & $37.5 \%$ \\
\hline Pinar del Rio & $30 \%$ \\
\hline Sancti Spiritus & $20 \%$ \\
\hline
\end{tabular}

As it was already mentioned, M. hypneumoniae has been historically recognized as the major etiological agent in pig pneumonias $(2,6)$. However, from works carried out by Andrada (3), M. hyorhinis strainswith a determined degree of virulence were observed to be enough to cause lesions in lungs. These findings suggest that in the chronic pneumonia, the concomitant infection by $M$. hyorhinis may increase the lesions of purulent bronchopneumonia causing pleurisy (12).

In the present study, the affected lung volume was not weighed up; only samples were taken from the affected areas regardless the lesion size and affected lobules. In this sense, studies about the characteristics and extension of the lesions, area and more affected lobules have been conducted, finding out their correlation with the isolate incidence or agent detection $(15,3)$.

Normally, the right lung has been observed to result more affected than the left one, showing a more abundant bronchogenic distribution (10) with the SEP lesions, varying according to the disease phase and the likely secondary complications at the moment of the inspection (3). In our case, the $66 \%$ of the samples resulted positive to M. hyorhinis, the highest percentage $(22.77 \%)$ was detected from lesions occurring in the apical lobule, the $20.37 \%$ in the mediastinal lobule and the $17.86 \%$ corresponded to lesions in the diaphragmatic lobule.

This result is similar to those achieved by Assuncao (4), where the highest number of detection of $M$. hyorhinis was reported in the left apical and mediastinal lobules. On the other hand, the highest percentage of positiveness detected in the present work about $M$. hyorhinis occurrence (66\%) agrees with that reported by Moorkamp (16) and Palzer (17). These authors carried out studies on the percentage of incidence of pathogenic microorganisms in swine pneumonias and their interrelation with other agents and, in both cases, they showed the highest incidence of $M$. hyorhinis detected in pneumonic lesions and its possible ship relation as another pathogen inside swine pneumonia.

Sequencing methods have been introduced as a new way to study the molecular epidemiology in bacterial pathogens (5). Within these methods, the sequencing of the intergenic region (IGR) of $16 \mathrm{~S}-23 \mathrm{~S}$ of the rRNA is a new weapon for epidemiological studies. Due to this region can be variable in sequence and size in different species of mycoplasmas, it has been used for the comparison of microorganisms of a same species or among species with a close phylogenetic relationship (19).

In our case, amplification of the intergenic region of the $16 \mathrm{~S}-23 \mathrm{~S}$ of the rRNA of $M$. hyorhinis was performed, and PCR results are shown in Figure 1, where the existing variability between strains of a same species is observed.

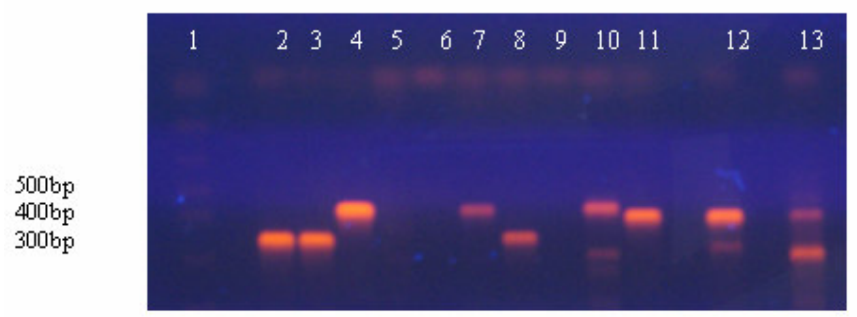

Figure 1. PCR on 2\% agarose gel of the IGR of the $16 \mathrm{~S}-23 \mathrm{~S}$ of the rRNA of $M$. hyorhinis strains detected in different regions of the island. Lane 1: molecular weight standard of 50-2000 bp., Lane 2: sample from Pinar del Río; Lane 3: sample from Matanzas; Lane 4: sample from La Habana; Lane 5 and 6: negative control; Lane 7: sample from Camagüey; Lane 8: sample from Villa Clara; Lane 9: negative control; Lane 10: sample from Ciego de Avila; Lane 11: sample from Cienfuegos; Lanes 12 and 13: positive control DNA (M. hyorhinis strain NCTC 10130) 
Similar results were obtained by Ravi (19) who reported the sequence of the IGR of the $16 \mathrm{~S}-23 \mathrm{~S}$ of the rRNA for Mycoplasma gallisepticum (MG) to be highly variable (with a discrimination index (D) of 0.950 between laboratory, vaccine and field MG strains, what permitted isolate differentiation for diagnostic purposes and in epidemiological studies. On the other hand, Ramiírez (18), performed genotypification studies among more than 20 species of avian mycoplasmas by sequencing the IGR of the $16 \mathrm{~S}-23 \mathrm{~S}$ of the rRNA. In this case, they pointed out the low polymorphism or variability present in this region among organisms of a same genus but different species.

These results are a contribution to the knowledge of the enzootic pneumonia and set the basis for more complete studies about the variability of $M$. hyorhinis strains and their possible pathogenic capability, studying in depth the IGR of this species. From these results, it can be said that M. hyorhinis is circulating in the western and central regions of the island, and the results achieved can contribute to the knowledge of the EP molecular epidemiology in Cuba.

Knowning the high incidence of $M$. hyorhinis in lung lesions and the possibility that strains of this microorganism can cause lesions similar to those observed in the EP, this can be a starting point for further studies correlating lesion location, incidence and pathogenicity of this agent under the conditions in Cuba.

\section{ACKNOWLEDGEMENTS}

This work was possible thanks to a Scholarship of the Spanish Agency of International Collaboration (AECID) and the cooperation and personal assistance of Dr. José B. Poveda and his staff.

\section{REFERENCES}

1. Abeledo, M.A.; Ruano, M.; Vega, E.; Lobo, E. and Ruedas, D. (2005). Detección de Anticuerpo frente a Mycoplasma gallisepticum mediante un
ELISA competitivo. Rev. Salud Animal. 27 (1), 21-25.

2. Amass, S.F.; Clark, L.K.; Van Alstine, W.G.; Bowersock, T.L.; Murphy, D.A.; Knox, K.E.; Albergts, S.R. (1994). Interaction of Mycoplasma hyopneumoniae and Pasteurella multocida infectious in swine. JAVMA. 204:102-107.

3. Andrada, M.; Espinosa de los Monteros, A.; Herráez, P.; Rodríguez, F.; Fernández, A. (2003). Patogénesis, signos clínicos y lesiones de la Neumonía Enzoótica Porcina. Porci. 74:47-68.

4. Assuncao, P. A. (2003). Aislamiento e Identificación de micoplasmas porcinos. Aplicación de la citrometría de flujo al estudio de Mycoplasma hyopneumoniae. Tesis Doctoral. Departamento de Morfología, Universidad de Las Palmas de Gran Canaria

5. Brown, D.; Whitcomb R.; Bradbury, J. (2007). Revised minimal standards for description of new species of the class Mollicutes (division Tenericutes) Int J Syst Evol Microbiol. 57(Pt 11), 2703-2719.

6. Calsamiglia, M.; Collins, J.E.; Pijoan, C. (2000). Correlation between the presence of enzootic pneumoniae lesions and detection of Mycoplasma hyopneumoniae in bronchial swabs by PCR. Vet. Microbiol. 76:299-303.

7. Caron, J., Ouardani, M., Dea, S. 2000a. Diagnosis and differentiation of Mycoplasma hyopneumoniae and Mycoplasma hyorhinis infections in PIGs by PCR amplification of the p36 and p46 genes. J. Clin. Microbiol. 38:1390-1396.

8. Fernández, C. and Chávez, Y. R. (1996). Aplicación de la reacción en cadena de la polimerasa en la detección de micoplasmas. Rev. Salud Animal 18 (1), 31-34.

9. Friis, N.F. (1971). Mycoplasma hyorhinis as a causative agent in arthritis of pigs. Acta Vet. Scand. 12:116-119.

10. Gomez-Villamandos, J.C.; Martin de las Mulas, J.; Quezada, M.; Carrasco, L. (1995). Patogenia y signos clinicos-cuadro lesiona de la Neumonía Micoplasmica Porcina. Porci. 27:19-33.

11. Johansson, K.E.; Heldtander, M.U.K. and Pettersson, B. (1998). Characterization of mycoplasmas by PCR and sequence analysis with universal 16S rDNA primers. In: R, Miles and R. Nicholas (eds). International book of Methods in Molecular Biology. Mycoplasma Protocols. USA, p. 145-165.

12. Kobisch, M. (2000). Mycoplasma diseases in Pigs - old diseases still causing trouble. 16th Internatinal Pig Vet. Society Congress, Melbourne, Australia, p. 434-438.

13. Lin, J.H.; Chen, S.P.; Yeh, K.S.; Weng C.N. (2006). Mycoplasma hyorhinis in Taiwan: Diagnosis and isolation of swine pneumonia pathogen. Veterinary Microbiology (115), 111-116.

14. Lobo, E. (2004). Micoplasmas de interés veterinario, Monographic of CENSA

15. Maes, D.; Verdonck, M.; Deluyker, H.; Kruif, A. (1996). Enzootic pneumonia in pigs. Veterinary Quartely. 18:104-109.

16. Moorkamp, L.; Heiko N.; Spergser B.; Tegeler R.; Grosse E. (2008). 
Detection of respiratory pathogens in porcine lung tissue and lavage fluid. The Veterinary Journal. 175 (2), 273-275.

17. Palzer, A.; Ritzmann, M.; Heinritzi, K.; Wolf, G. (2008). Associations between pathogens in healthy pigs and pigs with pneumonia. Veterinary Record. 162 (1), 267-271.

18. Ramírez, A.S.; Naylor C.J.; Pitcher D.G.; Bradbury, J.M. (2008). High inter-species and low intra-species variation in $16 \mathrm{~S}-23 \mathrm{~S}$ rDNA spacer sequences of pathogenic avian micoplasmas offers potential use as a diagnostic tool. Veterinary Microbiology 128: 279-287.

19. Raviv, Z.; Callison, S.; Ferguson-Noel, N.; Laibinis, V.; Wooten, R.; Kleven, S. H. (2007). The Mycoplasma gallisepticum 16S-23S rRNA
Intergenic Spacer Region Sequence as a Novel Tool for Epizootiological Studies. Avian Diseases 51:555-560.

20. Strait, E.L.; Madsen, M. L.; Minion, F.C; Christopher-Hennings, J.; Dammen, M.; Jones, K.R.; Thacker, E.L. (2008). Real-Time PCR Assays To Address Genetic Diversity among Strains of Mycoplasma hyopneumoniae J Clin Microbiol, pp. 2491-2498.

21. Volokhov, D. V.; George, J.; Sue X. L.; Ikonomi , P.; Anderson, C .; Chizhikov, V. (2006): Sequencing of the intergenic 16S-23S rRNA spacer (ITS) region of Mollicutes species and their identification using microarray-based assay and DNA sequencing. Appl Microbiol Biotechnol (71), 680-698. 